E26 菌株接种在落萢枝条上, 一个月后 仍能分离出大年接种物, 表明它能在植株伤 口附近定殖，产生农杆菌紊，竞争抑制根癌 土坮杆菌的僈人。'此外,消除了 $\mathrm{Ti}$ 质粒的根 豈土流杆菌对农杆菌亲 E26 也敏感，推测病 原囷对 E26 敏感性编码基因可能在染色体

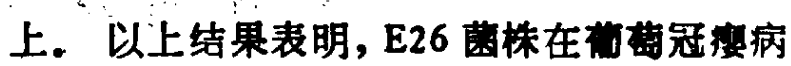
的生物防治中有应用前景.

\section{梁亚杰 狄原就”赵家英马德钦 （中国科学院机生物研究所，北京; \\ “北京农业大学植保系)}

\title{
鱼斯复眼光感受器生理变化作为时间和适应状态的函数 *
}

本文利用电生理细胞内记录方法, 在 $24 \mathrm{~h}$ 周期(日间和夜间)内和不同适应（明适应和 暗适应)状态下,持续记录. 研究了滀斯复眼 侧区小眼小网膜细胞的角灵敏度、光谱灵敏 度、偏振光灵敏度、绝对灵敏度和适应变化 的时间过程, 有关斯复眼的研究未见报 道.

1. 小网膜细胞的角灵敏度, 小网膜细胞 反应的幅度在给定的光强度下随着刺激光点 在细胞视场内位置的变化而变化. 当刺潡光 点在细胞光轴上时, 反应最大. 记录 20 个小 网膜细胞的平均值, 日间暗适应状态下, 水 平方向和垂直方向的平均接受角分别为 $2.2^{\circ}$ 和 $2.1^{\circ}$; 日间明适应状态下, 水平方向和垂 直方向的平均接受角分别为 $1.7^{\circ}$ 和 $1.6^{\circ}$. 夜 间暗适应状态下, 水平方向和垂直方向的平 均接受角分别为 $3.1^{\circ}$ 和 $2.9^{\circ}$; 夜间明适应状 态下, 水平方向和垂直方向的平均接受角分 别为 $2.0^{\circ}$ 和 $1.8^{\circ}$.

2. 小网膜细胞的光谱灵敏度, 日间和夜 间暗适应状态下 12 个小网膜细胞的光谱灵 敏度都有一个宽图的绿色波长峰 值 530 $550 \mathrm{~nm})$ 和一个小的紫外次峰值 $(370 \mathrm{~nm})$.

3. 小网膜细胞的偏振光灵敏度, 日间和 夜间暗适应状态下, 2 个小网膜细胞的偏振 光灵敏度值 (PS) 分别为 2.6 和 4.1, 这说明 都有偏振光灵敏度, 而且夜间更大. 这可能 因为全斯复眼光感受器结构上遵循一个生理 节律的变化, 日间, 光感受器的感杆束微线
毛破碎、脱落和变细短, 感杆束发生较大扭 转; 而夜间,由于感杆束微线毛重新生长、组 装和变粗长, 感杆束变得较小扭转. 感杆束 的偏振光灵敏度同它的扭转角度密切相关.

4. 小网膜细胞的绝对灵敏度, 20 个小网 膜细胞在日间和夜间,在明适应和暗适应时, 细胞反应的幅度是不同的. 日间小网膜细胞 反应的幅度小于夜间反应的幅度, 明适应时 的小网膜细胞反应幅度小于暗适应时的反应 幅度, 这就意味着小网膜细胞对光的绝对灵 敏度不同，夜间暗适应的小网膜细胞对光很 灵敏,显示了较高的绝对灵敏度.

5. 小网膜细胞适应变化的时间过程, 追! 踪一种适应状态到另一种适应状态的时间过 程, 就是从明适应状态到暗适应状态或者相 反的过程. 2 个小网膜细胞的接受角和绝对 灵敏度变化的时间过程表明，从完全暗适应 到完全明适应的时间过程快于相反的过程. 也就是从完全明适应状态过渡到完全暗适应 状态的时间过程大约需要 $1 \mathrm{~h}$, 而相反过程大 约需要 $0.5 \mathrm{~h}$.

\section{吴卫国 吴梅英 E. J. Warrant} 徐智敏石淑王翔 高奔张少吾

（中国科学院生物物理研究所，北京; 影大 利亚国立大学被觉科学中心，塂培位）

- 国家自然科学基金助项目.

报

1989 年 